\title{
Exploration on the Reform of Basic Course Teaching Based on Discipline Competition
}

\author{
Wang Yuci \\ Beijing University of Agriculture \\ Beijing 102206
}

\begin{abstract}
The combination of subject competition and basic course teaching can achieve the purpose of "promoting learning by competition and promoting competition by learning". In order to promote the reform of basic courses by subject competition, it is necessary to integrate the discipline competition into the basic course system, innovate the basic course teaching mode, deepen the cultivation of innovative ability in the basic course teaching, and innovate the evaluation system of the basic course teaching quality. To establish a guarantee mechanism for "promoting learning by competition and promoting competition by learning", it is essential to strengthen institutional construction, optimize teaching conditions, strengthen the construction of laboratories and practice bases, and strengthen the construction of competition guidance te achers.
\end{abstract}

Keywords—subject competition; basic course; teaching reform

The subject competition is a mass scientific and technological activity for college students. It examines students' basic knowledge and the ability to apply knowledge to solve practical problems in a competitive way based on classroom teaching, which plays an important role in cultivating students' innovative thinking, innovative ability and teamwork spirit. Since the launch of the National College Students Mathematical Modeling Competition in 1992, the discipline competitions of Chinese universities have gradually entered a period of vigorous development. There are many types of competitions and different levels of competition like national-level (international-level), provincial-level, school-level, popular basic academic competitions, and special skills competitions for some professional students. The number of people participating in the academic competitions increases year by year, up to several million, and colleges and universities are paying more and more attention to the participation of academic competitions.

Basic courses in colleges mainly refer to courses for students in the first and second years, including basic courses in mathematics, physics, chemistry, and public courses in foreign languages, sports, politics, and computers. The national subject competitions for basic courses mainly include the National College Students Mathematical Modeling Contest, the National College Students English Speech Contest, and the National Undergraduate Electronic Design Competition. The municipal competition includes the Beijing University Students Physics Experiment Competition, the Beijing University Student Chemistry Experiment Competition, etc..

\section{The Influence of SubJeCt Competition on the TEACHING REFORM OF BASIC COURSES}

\section{A. The subject competition provides a guide for the reform of} the basic course teaching

The subject competition combines basic knowledge and basic skills, combines common knowledge with experimental content, innovates experimental content and experimental methods, and promotes the reform of experimental practice teaching content. The subject competition is closely related to the reform of the basic course content, which is helpful for the construction of the basic course and the updating and improvement of the course system. Through the results of the student subject competition, we can see the students' mastery of knowledge and application ability, thus reflecting the reasonableness of teaching content and curriculum setting, timely discovering problems in teaching, and providing guidance for the reform of basic course teaching [1]. Therefore, by effectively integrating the subject competition with the basic course teaching, it is possible to achieve the purpose of promoting the quality of the basic course teaching by the subject competition. In addition, after students participate in various types of discipline competitions at home and abroad, their knowledge structure will be closer to the needs of social life and economic development, which at the same time put forward higher requirements for the instructor's subject knowledge and professional skills. Since the subject competition reflects the latest research trends and social hotspots of the subject with the characteristics of cutting-edge and innovation, so it points out the direction for the reform of the basic course to a certain extent

\section{B. The combination of the subject competition and the basic} course teaching realizes "to promote competition by learning and to promote learning by competition"

The basic course competition examines the students' basic knowledge and basic skills. Students select relevant themes according to their own interests during the competition, and use creative thinking, combined with social hotspots, to complete the competition in the form of teamwork. Through participation in the discipline competition, students completed projects for innovation and entrepreneurship. From the selection of the topic to the idea of creativity, from the writing of the thesis to the processing of the data, the students' hands-on ability is exercised, the teamwork spirit of the students is cultivated, and the students' horizons are broadened. 
These abilities are based on solid foundational knowledge and basic skills. Therefore, through the teaching mode of "promoting competition by learning and promoting learning by competition", it can not only cultivate students' innovative ability and practical ability, but also enhance students' mastery and application ability of knowledge. Through the combination of subject competition and basic course teaching and after a short period of time of high-intensity competition activities, excellent teaching results are often achieved, which is difficult to achieve in traditional basic classroom teaching[2].

\section{Promoting the Reform of Basic Course Teaching WITH SUBJECT COMPETITION}

\section{A. Innovative basic course content}

1) Integrate the discipline competition into the theoretical teaching system

Take the National College Students Mathematical Modeling Competition as an example, the knowledge points that are common in the competition can be incorporated into the mathematics curriculum and relevant courses with subject competitions can be integrated to optimize the theoretical teaching system. For example, Beijing Agricultural College has established Mathematical Modeling, Advanced Mathematics, Mathematical Culture, etc. in conjunction with the National College Students Mathematical Modeling Competition, opened Application of Physics Theory and Technology in Related Major combined with the physics experiment competition for college students, and Chemical Experiments and Social Life, Chemical Discovery and Creative Thinking, Chemical Synthesis and Design Experiments in conjunction with the College Student Chemistry Experiment Competition. Aiming at the students' academic level, we have carried out hierarchical courses and teaching, which has impelled more students to participate in the learning and training of relevant knowledge and skills in the subject competition and meantime provided excellent talents for the smooth development of the discipline competition[3].

2) Integrate the discipline competition into the practical teaching system

The content of the subject competition is incorporated into the experimental teaching content in the form of experimental projects, the experimental teaching materials are updated, and the knowledge points of the subject competition are integrated with the experimental content, so as to form a curriculum system with perfect curriculum system, advanced experimental content and reasonable course structure. Taking the national college students' electronic design competition as an example, the electronic technology, circuit, and single-chip technology involved in the electronic design competition are integrated with the experimental content of the students, the application experiment is added[4], a four-level experimental teaching system consisting of basic experiments, design experiments, comprehensive experiments, and applied experiments is constructed, so that students can gradually carry out scientific research training in experimental teaching to achieve the purpose of cultivating students' innovative ability and practical ability.

\section{B. Innovative basic course teaching mode}

The traditional basic course teaching mode is that the teacher speaks on the stage and students listen to the teacher and the teacher-led and student-centered teaching mode is implemented. The subject competition provides a good opportunity for the innovative basic course teaching mode. The teacher can set the subject competition project as the theme of the class, guide the students to participate actively, transform the classroom teaching into the project teaching state, and the students select the theme and content according to their own interests, and complete the project planning and implementation under the guidance of the teacher. Teachers encourage students to participate in competitions in teams to develop their teamwork and innovation skill, which has changed the traditional cramming teaching mode to a certain extent and mobilized students' enthusiasm and initiative.

\section{Deepen the cultivation of innovation ability in basic course teaching}

The subject competition reflects the students' innovative consciousness and innovative ability. In the basic course teaching, it is necessary to deepen the cultivation of students' innovative consciousness and innovative ability. Taking the Basic Education Department of Beijing Agricultural College as an example, the mathematics, physics, and English teaching and research sections under it are adjusted and optimized from the aspects of guiding ideology, teaching objectives, curriculum system to cultivate students' innovative awareness and innovative ability. The university mathematics teaching and research section implements a two-way selection mode for teachers and students of various majors. Teachers select appropriate professional classes according to their professional expertise and hobbies, and integrate basic course knowledge with professional course knowledge to inspire students to learn professional knowledge, laying a good foundation for future professional courses. Meantime, we should implement hierarchical and sub-module teaching in teaching, divide mathematics curriculum into compulsory courses and elective courses, enable students to grasp the necessary basic knowledge of mathematics through the compulsory courses to meet the needs of students' professional courses in the future. For students who have spare time, we should provide more learning channels and offer mathematics elective courses in different semester, such as Mathematical Modeling, Advanced Mathematics, Mathematical Culture, University Mathematics Experiment, etc. Besides, we should hire out-of-school teaching teachers to give lectures to the school every semester, so that students can reach more mathematics culture, improve students' horizons, train students to love and explore the spirit of love and innovation, and lay a good foundation for students to participate in mathematics courses or postgraduate studies.

\section{Evaluation system of teaching quality of basic courses}

The traditional quality evaluation of basic courses emphasizes the mastery of basic knowledge. It mainly measures the teaching effect of teachers based on the scores of students' final exams but lacks the necessary attention to the assessment of students' innovative thinking and innovative ability. The subject competition examines the students' basic knowledge and basic skills, which is a special test that is 
derived from classroom teaching and higher than classroom teaching. Through the subject competition, on the one hand, the teaching tasks are completed, and the students' learning effects and knowledge mastery are tested. On the other hand, by competing with other college students, they can find out their own advantages and gaps and continuously improve the teaching quality. Therefore, it is necessary to pay attention to the cultivation of students' comprehensive ability in the context of academic competition, the cultivation of students' innovative thinking and creative ability, and the practical ability of students and the cultivation of practical ability to solve problems. At the same time, the content of the examination should be reformed to guide the diversified development of the examination content[5]

\section{Establish A Guarantee Mechanism to Promote} LEARNING BY COMPETITION AND PROMOTE COMPETITION BY LEARNING

\section{A. Strengthen system construction, scientific and standardized management}

Establishing a management system for academic competitions and implementing scientific and standardized management can ensure the smooth progress of the teaching of the subject competition and the basic course, and improve the enthusiasm of teachers and students. In terms of the organizational mechanism, management mechanism, incentive mechanism, and safeguard mechanism of the discipline competition, there should be rules and regulations, and special personnel. Disciplinary competition committees should be set up to plan various discipline competitions; the standing committee of discipline competitions should be established to be responsible for the daily affairs of the discipline competitions; the expert committee of discipline competitions should be set up to guide or review the discipline competitions. Appropriate incentives can stimulate the enthusiasm and enthusiasm of teachers and students to participate in the discipline competition. Therefore, it is necessary to give credits to students participating in the discipline competition, give material and spiritual rewards to the award-winning students, give incentives to the instructors who participate in the discipline competitions, and give a tilt when the titles are reviewed and evaluated first. In the process of implementing the reform of the subject competition into the basic course teaching reform, it is necessary to set up special funds for the competition for the necessary expenses in various competition activities and teaching reforms. Reasonable funding is the material basis for ensuring the smooth development of the discipline competition and the smooth progress of the basic course teaching reform.

\section{B. Optimize teaching conditions and strengthen the construction of laboratories and practice bases}

To achieve effective integration of the subject competition and the basic course teaching requires good teaching conditions. It is necessary to strengthen the construction of laboratories and the construction of practice bases to provide students with good environmental conditions for participating in academic competitions. The school-level basic course experiment center should be set up to realize the optimal allocation of experimental resources and high-quality equipment, gradually establish an open laboratory, open to all students, and improve the utilization of instruments and equipment. In addition, it is crucial to strengthen close cooperation between industry, academia and research, and to establish innovative laboratories, simulation laboratories or practice bases through school-enterprise cooperation to provide students with good conditions for scientific research and academic competition.

\section{Strengthen the construction of the instructor team and improve the ability of scientific research and innovation}

Only teachers with strong scientific research ability and innovative ability can better guide students to participate in academic competitions and improve students' innovative thinking ability and practical ability. However, basic course teachers usually graduate from comprehensive colleges. Generally speaking, they have strong theoretical knowledge of disciplines, but they often lag behind professional teachers in basic skills and innovative abilities. Therefore, it is first essential to strengthen the construction of the basic course teachers and improve their research and innovation capabilities. Beijing Agricultural College conducts the "Basic Course Teacher Experimental Skills Competition” every year, which effectively promotes the improvement of experimental skills and hands-on ability of young teachers. Secondly, colleges and universities should pay attention to the construction of the basic course laboratory teachers, recognize that experimental technicians are an important force in experimental teaching and scientific research in colleges and universities and they play an important role in the cultivation of college students' innovative ability and practical hands-on motivation. Therefore, it is of great significance to improve the treatment of experimental technicians and stimulate the enthusiasm and initiative of experimental technicians. Third, a sound training system should be established to give the discipline competition instructors and experimental technicians the opportunity to fully learn and improve their professional quality, encourage them to "go global", participate in professional skills training or business ability training, and improve their research and innovation capabilities to meet the needs of academic competition and basic curriculum reform.

\section{CONCLUSION}

The discipline competition of colleges and universities has entered a period of vigorous development. The discipline competition helps to promote the cultivation of students' innovative thinking ability and has an important influence on the reform of basic course teaching. Through the innovation of the basic course content, the innovative basic course teaching mode, the deepening of the cultivation of innovative ability in the basic course teaching, and the evaluation system of the innovative basic course teaching quality, the aim of promoting the basic course teaching reform by subject competition is realized. It is necessary to strengthen the system construction, optimize the teaching conditions, strengthen the construction of the teaching staff, and establish a guarantee mechanism for "promoting competition by learning and promoting learning by competition”. 


\section{REFERENCES}

[1] Guo Tao \& Hu Xiaojuan. Exploration and Practice of Incorporating Curriculum Competition into Curriculum System[J]. China Electronics Education, 2016(2): 73-76.

[2] Fan Zheng. Research on Photography Course Teaching Based on Discipline Competition[J]. Beauty and the Times (I), 2016, (10): 117-118.
[3] Wang Yuci. Exploration of Disciplinary Competition System for the Cultivation of Excellent Agriculture and Forestry Talents[J]. Education and Teaching Forum, 2015, (14): 127-129.

[4] Xue Yanru, Liu Min, Zhao Wei et al. Enhancing the Innovation Ability of Local College Students by Relying on Discipline Competition[J]. Journal of Experimental Technology and Management, 2013, 30(6): 170-173.

[5] Zhi Leiying. Research on Effective Integration of Photography Teaching and Discipline Competition [J]. Art Education Research, 2018, (12): 124 